\title{
Alternative four-factor structure of the Mini-IPIP in Thailand
}

\author{
Ronald Fischer \\ Institute D’Or for Research and Teaching, Rio de Janeiro, Brazil \\ \& Victoria University of Wellington, New Zealand
}

\begin{abstract}
This paper reports on the first study of the structure of the Mini-IPIP in Thailand. A modified version was used that included additional Honesty-Humility items. A four-factor structure was found in a Southern Thai community sample $(N=212)$, that did not match previously reported factor structures. When using a separate student sample $(N=201)$, the structure was partially replicated. Two socially oriented dimensions (Social Approach versus Social Withdrawal; Traditional Affiliation), Neuroticism, and a broad Egotism factor capturing low Humility and low Conscientiousness items, emerged. The trait structure in this non-Western sample shows some meaningful divergence from standard fivefactor models, suggesting possible cultural modulation of basic personality descriptions.
\end{abstract}

Keywords: personality, traits, IPIP, culture

There is general consensus that personality in Western samples can be described in five major dimensions, the so-called Big Five or Five-Factor model (FFM) of personality (Goldberg, 1990; McCrae \& John, 1992), comprising Conscientiousness (C), Agreeableness (A), Neuroticism (N), Openness (Intellect) $(\mathrm{O} / \mathrm{I})$ and Extraversion $(\mathrm{E})$. Yet, a significant number of recent studies with non-Western and non-student samples has suggested that personality structures cannot be replicated or are organized differently depending on the local cultural and social context (Cheung et al., 2001; Church et al., 2011; De Raad et al., 2014; Laajaj et al., 2019; Nel et al., 2012; Saucier et al., 2014; Schmitt et al., 2007; Thalmayer et al., 2020). Applications of Big Five instruments in mainly student samples from around the world have shown relatively consistent levels of replication in most Western nations, but indeed with relatively poorer replicability in many of the African and some Asian samples (Church et al., 2011; Laajaj et al., 2019; McCrae, 2001; McCrae et al., 2005; Schmitt et al., 2007). The only Thai sample available to date was an observer report in McCrae et al. (2005) which showed generally satisfactory factor congruence with the US target structure (but with some problems for the Openness factor). Gurven et al. (2012) administered a 44-item FFM inventory to a large sample of Tsimane forager-horticulturalists in the Amazonian low-lands in Bolivia. Using both self- and spouse-reports, the target rotated factor structure showed poor congruence with the US target structure. An exploratory factor analysis of the data suggested two stable factors that were replicated across both self- and spouse reports. The first factor captured a number of $\mathrm{E}$ and $\mathrm{A}$ items and was labelled Prosociality. The second factor had load-

Correspondence concerning this article should be addressed to Ronald Fischer, Instituto D'Or de Pesquisa e Ensino, Rua Diniz Cordeiro, 30 Botafogo - Rio de Janeiro - RJ, CEP 22.281-100, Brazil.

E-mail: Ronald.Fischer@idor.org or Ronald.Fischer@vuw.ac.nz ings of a number of C items and was called Industriousness.

The previous studies were based on applications of existing questionnaires in culturally-diverse samples. A different option is to start off with person descriptions in each language and to derive a factor structure based on culture- and language-specific data. Culture-specific studies have suggested that additional factors or more differentiated factors may emerge within non-Western cultures. For example, Cheung developed a series of studies in Chinese societies (Cheung et al., 2001; 2008) which found an additional interpersonal relatedness factor. A research program using person descriptions in eleven indigenous languages in South Africa (Nel et al., 2012; Valchev et al., 2013; 2014) found a larger number of clusters that differentiate social-relational aspects of relevance in more collectivistic and group-oriented cultures. According to Ashton et al. (2004) and Ashton and Lee (2005; 2007), psycho-lexical studies comprise six instead of five major factors, forming the so-called HEXACO model of personality (Honesty-Humility, Emotionality, Extraversion, Agreeableness, Conscientiousness, Openness/Intellect). Three of the factors (C, E, and O/I) were straight replications of the traditional Big Five. Agreeableness and Emotionality differed from $\mathrm{A}$ and $\mathrm{N}$ in the Big Five tradition by rotating some dimension content (Ashton \& Lee, 2007). HEXACO Emotionality captures emotional reactivity rather than emotional instability, excludes Anger (part of $\mathrm{N}$ in the Big Five) and includes sentimentality (part of A in Big Five). Agreeableness in the HEXACO model excludes sentimentality and includes lack of anger. Therefore, the A factor in the HEXACO model is less emotionally-charged and captures the more interpersonal aspects of patience, tolerance and peacefulness. The additional sixth factor is Honesty-Humility, which captures some content that is included in the A factor of the Big Five (De Raad et al., 2014). This factor is characterized by personality traits related to sincerity, fairness, being unpretentious and a lack of greed. 
These claims of a possibly universal five or six factor structure created significant interest. Yet, other lexical studies of personality descriptions only recovered two (Saucier et al., 2014) or three (De Raad et al., 2010; 2014) factors consistently across cultures. De Raad et al. (2010) reported that three factors (related to E, A, C) formed the most consistent and stable personality configuration across their samples. Saucier et al. (2014) reported the emergence of two big factors across cultures, which they labelled Social Self-Regulation and Dynamism (see also De Raad et al., 2014). The first of these two factors was strongly related to aspects of communion, morality, warmth, interpersonal nurturance, and absence of externalizing problems. The second was characterized by correlations with factors capturing agency, competence, dominance, and absence of internalizing problems, possibly suggesting relations to biological process variables (e.g., reward sensitivity). Some similarities of these two factors with the factors Industriousness and Prosociality reported in Gurven et al. (2012) are noticeable.

In summary, when applying Western personality questionnaires to non-Western (primarily student) samples with high levels of education, five factors are typically encountered, although factor congruence can be marginal in some Asian and African populations. When studying samples with lower levels of education and outside a self-selected internet context, factor structures tend to replicate more poorly (Laajaj et al., 2019). It is possible that simpler structures emerge in socioeconomically poorer contexts where individuals do not have the resources or opportunities to differentially express behavioral predispositions (Fischer, 2017; Lukaszewski et al., 2017).

In this paper, I report on the translation and application of a short personality measure based on the Big Five with an added sixth Honesty-Humility factor (Donnellan et al., 2006; Sibley et al., 2011) in Thailand. There has been a dearth of studies in the international literature that have explicitly tested Western personality tests, which makes Thailand an interesting study context. The only paper published in international peer-reviewed journals to the best of my knowledge is the observer report data from McCrae et al. (2005), which showed poorer replication of the Big Five structure. Thailand is located in South East Asia and has never been formerly colonized by a Western nation, which has led to maintenance of traditional cultural structures and greater cultural continuity over the centuries. It is a culturally diverse nation, but with a strong collectivistic and community orientation and more traditional cultural values (Hofstede, 2001; Inglehart \& Baker, 2000). Hence, it is worth exploring the applicability of a personality measure in this culturally distinct context.

I report on data from two Thai samples, including one community sample, using a short instrument to measure personality that has been used with US, Canadian, British, New Zealand, and Chinese participants (Baldasaro et al., 2013; Cooper et al., 2010; Donnellan et al., 2006; Li et al., 2012; Sibley et al., 2011).

\section{Study 1}

The first study administered a new translation of the miniIPIP6 (Sibley et al., 2011). Given the challenges of replicating personality structures in community samples, it presents a first challenge for the replicability of the personality structure in this more traditional context.

\section{METHOD}

\section{Participants}

A total of 212 community members (114 males) participated. The mean age was 26.9 years $(S D=10.1)$. Participants were recruited in the main streets of a large town in Southern Thailand and they were invited to answer a short survey.

\section{Measures}

I used an adapted version of the Mini-IPIP (Donnellan et al., 2006) which included four honesty-humility items developed by Sibley et al. (2011). After discussion with local community members, I used a 6-point Likert-type scale ranging from 1 (completely agree) to 6 (completely disagree). The items were translated by a bilingual psychologist in discussion with the author to clarify the meanings of each item. The translated version was then checked by a university professor in Thailand and by a professional translator. Minor adjustments were made for each item. The final version was discussed with a sample of 20 community volunteers and no further adjustments deemed necessary.

\section{RESULTS AND DISCUSSION}

I first conducted a confirmatory factor analysis with MPlus6 (Muthen \& Muthen, 2011). I used the structure reported by Sibley et al. (2011) with five factors as found in the standard Mini-IPIP and four added honesty-humility items. I removed nine individuals that did not discriminate between questions. The six-factor structure did not fit well: $\mathrm{X}^{2}$ (237, $N=198)=918.77, p<.0001, \mathrm{RMSEA}=.121, \mathrm{CFI}=.59$, $\mathrm{TLI}=.52, \mathrm{SRMR}=.116$. All fit indices indicated poor model fit of the data to the hypothesized model. This is a common finding in the personality literature (Marsh et al., 2004; McCrae et al., 1996), and it has also been reported for mini-IPIP applications (Baldasaro et al., 2013; Cooper et al., 2010).

An alternative strategy recommended for fitting personality structures is Procrustean Factor Rotation (McCrae et al., 1996). I used the original six factor structure from a representative sample of NZ citizens (Sibley et al., 2011) as input and used established guidelines for examining factor similarity (Fischer \& Fontaine, 2011; Fischer \& Karl, 2019).

Table 1 reports on the factor loadings after procrustean rotation. Inspecting the factor loadings, all but three items loaded highest on their specified factor after rotation. However, loadings were relatively uneven and a number of sizeable cross-loadings can be observed. To quantify the resemblance, factor congruence coefficients of .90 or higher are taken as adequate (Fischer \& Fontaine, 2011; Fischer \& Karl, 2019). As Table 1 shows, I found poor factor recovery across all indicators (mean Tucker's phi $=.60$ ). Even using the more lenient criterion of .85 (ten Berge, 1986), only the first factor, loaded by $\mathrm{O} / \mathrm{I}$ items, showed statistical resem- 
Table 1. Procrustean target rotated loadings of exploratory factor analysis

\begin{tabular}{|c|c|c|c|c|c|c|}
\hline & 1 & 2 & 3 & 4 & 5 & 6 \\
\hline E-01 Am the life of the party & 0.09 & 0.07 & -0.04 & 0.18 & 0.60 & -0.38 \\
\hline E-02 Don't talk a lot (r) & 0.21 & 0.10 & -0.02 & 0.25 & 0.36 & -0.25 \\
\hline E-03 Keep in the background (r) & 0.25 & 0.11 & -0.11 & 0.24 & 0.45 & -0.23 \\
\hline E-04 Talk to a lot of different people at parties & 0.05 & 0.01 & 0.04 & 0.28 & 0.54 & -0.31 \\
\hline A-01 Sympathize with others' feelings & 0.07 & -0.25 & 0.72 & 0.02 & -0.03 & -0.08 \\
\hline A-02 Am not interested in other people's problems (r) & 0.31 & -0.07 & 0.26 & 0.08 & -0.05 & 0.02 \\
\hline A-03 Feel others' emotions & 0.06 & -0.20 & 0.66 & -0.04 & -0.05 & -0.11 \\
\hline A-04 Am not really interested in others (r) & 0.34 & -0.13 & 0.34 & 0.12 & 0.00 & 0.00 \\
\hline C-01 Get chores done right away & -0.15 & 0.23 & 0.23 & -0.12 & 0.37 & 0.36 \\
\hline C-02 Like order & -0.16 & 0.24 & 0.24 & -0.22 & 0.28 & 0.35 \\
\hline C-03 Make a mess of things (r) & 0.14 & 0.02 & 0.02 & -0.11 & 0.30 & 0.48 \\
\hline C-04 Often forget to put things back in their proper place (r) & 0.10 & 0.25 & 0.09 & -0.08 & 0.27 & 0.45 \\
\hline $\mathrm{N}-01$ Have frequent mood swings & 0.05 & 0.63 & 0.11 & -0.15 & -0.15 & -0.28 \\
\hline $\mathrm{N}-02$ Am relaxed most of the time (r) & 0.11 & 0.49 & 0.07 & -0.09 & -0.20 & -0.08 \\
\hline N-03 Get upset easily & -0.09 & 0.49 & 0.23 & -0.13 & -0.11 & -0.23 \\
\hline N-04 Seldom feel blue (r) & 0.17 & 0.40 & 0.05 & -0.14 & -0.18 & -0.07 \\
\hline O-01 Have a vivid imagination & 0.34 & 0.18 & 0.01 & -0.09 & -0.01 & -0.12 \\
\hline O-02 Have difficulty understanding abstract ideas (r) & 0.66 & -0.04 & -0.16 & -0.12 & -0.10 & 0.18 \\
\hline O-03 Do not have a good imagination (r) & 0.51 & 0.06 & -0.08 & -0.04 & -0.02 & 0.05 \\
\hline O-04 Am not interested in abstract ideas (r) & 0.67 & -0.03 & -0.03 & -0.08 & -0.13 & 0.11 \\
\hline $\mathrm{H}-01$ Feel entitled to more of everything (r) & -0.06 & 0.05 & 0.09 & 0.52 & -0.13 & 0.22 \\
\hline $\mathrm{H}-02$ Deserve more things in life $(\mathrm{r})$ & -0.04 & 0.16 & 0.04 & 0.67 & -0.13 & 0.21 \\
\hline $\mathrm{H}-03$ Would like to be seen driving around in a very expensive car $(\mathrm{r})$ & -0.03 & 0.27 & 0.06 & 0.62 & -0.24 & 0.26 \\
\hline H-04 Would get a lot of pleasure from owning expensive luxury goods (r) & -0.06 & 0.24 & 0.03 & 0.64 & -0.18 & 0.19 \\
\hline Tucker's Phi & .80 & 68 & .60 & .64 & .44 & .46 \\
\hline Cronbach's alpha & .66 & .63 & .53 & .75 & .55 & .40 \\
\hline
\end{tabular}

blance to the factor structure found in a representative sample of NZ adults. The reliabilities for the original structure were relatively low. The factor loaded by Honesty-humility items (factor 4) showed sufficient reliability and both Openness (factor 1) and Neuroticism (factor 2) showed internal consistencies above .60, which may be sufficient for research instruments.

I therefore conducted further exploratory analyses to identify plausible structures. Exploratory Graph Analysis has been suggested as a robust method for identifying optimal factor numbers in high-dimensional data structures (Golino et al., 2020; Golino \& Epskamp, 2017). I ran a bootstrapped (resampling) Exploratory Graph Analysis with 1000 bootstrap samples and a walktrap clustering algorithm. A single factor emerged in less than $1 \%$ of the solutions, two factors in $32.1 \%$ of the solutions, three factors in $41.3 \%$ and four factors in $20.5 \%$, while five factors emerged in $4.7 \%$ of the bootstrap samples. I therefore extracted both three and four factor solutions using Exploratory Factor Analysis with varimax rotation. The Eigenvalues of the first four factors were $3.72,2.74,2.13$, and 2.09 and these explained $15 \%$, $11 \%, 9 \%$ and $9 \%$ of the extracted variance, respectively. I report on the four-factor structure in Table 2, because the three-factor structure merges factor 2 and 4 into a single factor. The three factor solution explained $47.48 \%$ of the variance, whereas the four-factor solution explained $53.70 \%$ of the total variance.
The first factor had loadings primarily from $\mathrm{O}, \mathrm{A}$ and $\mathrm{E}$ items. These items capture a sense of social withdrawal and lack of curiosity in intellectual and social issues. Although the highest loading item is $\mathrm{O}-04$ (not interested in abstract ideas), the other loadings of A-04 (not interested in others), E-03 (keep in the background), A-02 (not interested in other people's problems) and E-02 (don't talk a lot) suggest a more social dimension. Being involved and taking a keen interest in other people's life is a central activity in interpersonally-oriented communities. In the highly collectivistic and group-oriented context of this sample, the emergence of these items as a factor seems to suggest a negative trait cluster of social withdrawal and disinterest in the matters of others. Therefore, I labelled it 'Social Withdrawal (vs. Social Approach)'.

Factor 2 captured three of the four $\mathrm{N}$ items and I therefore labelled this factor 'Neuroticism'. O-01 (vivid imagination) loaded highest on this factor, which may be compatible with an orientation towards rumination (ceaseless consideration of problems and their possible outcomes). This item also showed cross-loadings on $\mathrm{N}$ in the representative sample by Sibley et al. (2011). It is interesting to note that the reversely coded N4 (seldom feel blue - translated as 'rarely depressed') loaded positively on this factor. Although it may indicate some response bias, I believe it is more likely to reflect substantive factors. The item shows 


\begin{tabular}{|c|c|c|c|c|}
\hline & $\begin{array}{c}\text { Social } \\
\text { Withdrawal }\end{array}$ & Neuroticism & Affiliation & Egotism \\
\hline $\mathrm{O}-04$ Am not interested in abstract ideas (r) & 0.82 & 0.06 & 0.09 & 0.14 \\
\hline A-04 Am not really interested in others (r) & 0.77 & 0.22 & -0.05 & 0.24 \\
\hline O-03 Do not have a good imagination (r) & 0.67 & 0.03 & 0.18 & 0.16 \\
\hline O-02 Have difficulty understanding abstract ideas (r) & 0.60 & 0.30 & 0.17 & 0.09 \\
\hline E-03 Keep in the background (r) & 0.58 & 0.04 & 0.20 & 0.01 \\
\hline A-02 Am not interested in other people's problems (r) & 0.55 & 0.20 & -0.02 & 0.27 \\
\hline E-02 Don't talk a lot (r) & 0.40 & 0.11 & 0.22 & 0.06 \\
\hline O-01 Have a vivid imagination & -0.04 & 0.72 & 0.24 & 0.13 \\
\hline $\mathrm{H}-01$ Feel entitled to more of everything (r) & 0.11 & 0.63 & 0.32 & 0.18 \\
\hline $\mathrm{N}-01$ Have frequent mood swings & 0.19 & 0.60 & 0.07 & 0.14 \\
\hline N-03 Get upset easily & 0.29 & 0.52 & -0.07 & 0.14 \\
\hline N-04 Seldom feel blue (r) & 0.28 & 0.45 & 0.07 & 0.15 \\
\hline E-01 Am the life of the party & 0.01 & 0.44 & 0.36 & 0.26 \\
\hline A-03 Feel others' emotions & 0.07 & 0.11 & 0.62 & 0.11 \\
\hline $\mathrm{N}-02$ Am relaxed most of the time (r) & 0.28 & -0.01 & 0.62 & 0.16 \\
\hline A-01 Sympathize with others' feelings & 0.07 & 0.07 & 0.59 & 0.13 \\
\hline C-02 Like order & 0.31 & 0.12 & 0.40 & -0.17 \\
\hline C-01 Get chores done right away & 0.03 & 0.26 & 0.38 & -0.03 \\
\hline H-02 Deserve more things in life (r) & 0.30 & 0.33 & 0.36 & 0.30 \\
\hline H-04 Would get a lot of pleasure from owning expensive luxury goods (r) & 0.15 & 0.14 & 0.13 & 0.84 \\
\hline H-03 Would like to be seen driving around in a very expensive car (r) & 0.27 & 0.42 & 0.00 & 0.50 \\
\hline E-04 Talk to a lot of different people at parties & 0.11 & 0.27 & 0.25 & 0.48 \\
\hline C-03 Make a mess of things (r) & 0.34 & 0.27 & 0.00 & 0.44 \\
\hline C-04 Often forget to put things back in their proper place (r) & 0.37 & 0.21 & 0.17 & 0.41 \\
\hline Cronbach's alpha & .85 & .78 & .71 & .78 \\
\hline
\end{tabular}

Note: E, A, C, N, O, \& H respectively represent Extraversion, Agreeableness, Conscientiousness, Neuroticism, Openness, and Honesty. $\mathrm{r}=$ reverse.

some weak secondary loading on the first 'Social Withdrawal' factor. In addition, the other two $\mathrm{N}$ items capture hostility (N-03 'upset' was translated with a word implying 'angry'). The remaining items (H-01: feel entitled and E01: life of the party) also capture personality traits that describe a self-focused individual, bordering on a narcistic or histrionic description of a person.

Factor 3 is defined by strong loadings of the two emotion-focused A items and an Emotional Stability item (N02: relaxed most of the time). This is reminiscent of the first factor found by Gurven et al. (2012) in a traditional Tsimane sample. All these items capture a prosocial orientation or affiliation (Katigbak et al., 1996). Two C items also loaded moderately high on this factor (C-02: Like order; C-01: Get chores done), suggesting an inclination to fit into the larger order and actively contributing to maintaining order. I therefore labelled this factor 'Traditional Affiliation'.

The final factor had loadings from two of the negative Honest-Humility items, two reversed $\mathrm{C}$ items (C-03: make a mess; C-04: forget to put things back) and one $\mathrm{E}$ item (E04: talk to a lot of different people at parties). The combination of the reversed $\mathrm{H}$ and $\mathrm{C}$ items together with the negative connotation in this cultural context associated with talking to a lot of people may imply a personality profile of an individual geared towards a hedonistic and luxurious lifestyle without consideration of others. Such individuals pursue pleasure and luxury, may act carelessly with material things and do not put them back in their proper place. Therefore, I named this factor 'Egotism'. The second and last factor shared a negative connotation, with a focus on self-centered and emotionally charged behaviors. When extracting a three factor solution, these 'Neuroticism' and 'Egoism' factors merge into one larger factor, suggesting that these two factors may be more similar with each other.

This structure was reported in a community sample. Much of previous personality research has been conducted with student samples. Therefore, it is important to evaluate whether this structure is sample specific. I therefore attempted to replicate the structure in a more highly educated and younger sample of young adults studying at a local large university.

\section{Study 2}

\section{METHOD}

A student sample ( $N=201,89$ males) of undergraduate and Masters students at the largest university in Southern Thailand participated in this study. Mean age was 24.0 years $(S D=4.4$ years). The same survey as in study 1 was used. Participants completed the survey at the university during class time. 


\section{RESULTS}

I tested whether the four-factor structure from Study 1 was replicated in Study 2. Given the problems with confirmatory factor analysis, I used procrustean rotation as in study 1 . A minimum residual analysis (Revelle, 2021) revealed six factors with Eigenvalues larger than 1. These six factors together explained $38 \%$ of the variance. An Exploratory Graph Analysis using 1000 bootstrap samples and a walktrap clustering algorithm showed a modal structure of three factors (30.6\% of the solutions), followed by four factor structures $(26.4 \%)$. Therefore, I extracted both three (29\% explained variance) and four factor structures (33\% explained variance). I then rotated them to maximal similarity with the previously described "community" structure. The Tucker's phi values were $.93, .93$, and .79 for the three factor structure. This suggests that the 'Traditional Affiliation' factor was not well replicated in this younger cohort. For the four-factor solution, Tucker's Phi values were .94, $.91, .70$, and .79. This suggests that factor 1 (Social Withdrawal) and 2 (Neuroticism) were clearly replicated, whereas factors 3 (Traditional Affiliation) and 4 (Egoism) showed some divergence across the community and student samples. This second sample consisted of participants attending university, suggesting that education may have an influence on the structure of personality traits in Thai samples.

\section{DISCUSSION}

I reported on a brief self-report personality measure in Thailand, extending previous research in a number of directions. The trait structure that was found in the used samples differed in some meaningful way from standard five- or sixfactor models in the Western literature, suggesting that local context may modulate the expression of personality as captured by self-report measures (Fischer, 2017; Gurven et al., 2013; Gurven, 2018).

I could not replicate the six-factor personality structure found in NZ samples nor the proposed theoretical structure. Only O/I showed some statistical resemblance to factors found in previous samples. It is interesting to note that the Intellect components of O/I was not replicated in the studies by de Raad and colleagues (De Raad et al., 2010; 2014), but research in South Africa suggested clear O-related factors in a number of African languages (Nel et al., 2012; Thalmayer et al., 2020). When examining the structure of the subsequent exploratory factor analysis, the $\mathrm{O} / \mathrm{I}$-items that capture interest, lack of imagination and difficulty to understand abstract ideas merged with those Agreeableness items that focus on (the life of and the interest in) other individuals. Together, I interpreted this as a dimension of social approach vs withdrawal/disengagement. Traits related to $\mathrm{O}$ may take on a particular social orientation and function in non-Western contexts (Nel et al., 2012). However, it is also important to highlight the difficulty to adequately cover a complex trait such as $\mathrm{O} / \mathrm{I}$ within a short instrument.

I found a factor resembling $\mathrm{N}$. This may be expected given the strong biological basis that is thought to underlie $\mathrm{N}$ across a large number of samples. The opposite loading of the depression-related item is noteworthy. It may indicate that $\mathrm{N}$ in these samples were associated with hostility rather than with self-centred withdrawal and depression-like behavioral expressions. The culture-specific expression of biologically sustained personality dimensions requires more attention (Gurven et al., 2013). At the same time, the original term 'seldom feeling blue' was not translatable. Instead, an expression indicating 'rarely depressed' was used, but the negation may have made the item difficult to comprehend.

Reflecting work by Ashton and Lee (2007), a more narrowly defined $\mathrm{H}$ factor emerged that also captured a number of items related to $\mathrm{C}$ (indicating carelessness with material things). Wanting luxury goods and showing off one's wealth may be signals of social status (access to material resources) and indicate a lack of humility. This underscores the importance to pay more attention to $\mathrm{H}$ as a potential personality factor in a global perspective. The merger of the $\mathrm{N}$ and putative $\mathrm{H}$-factor are also worth exploring further. It may suggest that emotional processing and expression are connected to social status expressions within more hierarchical traditional societies.

Finally, a factor emerged with strong loadings from A items together with other items that refer to a relaxed and orderly, but also very sociable personality. This may fit observations that interpersonal orientations are important in more collectivistic contexts (Cheung et al., 2001; 2008; Cheung et al., 2011; Nel et al., 2012). Overall, the structure shows some resemblance to traditional Big Five factors, but it suggests that the expression of universal biological dispositions that are assumed to underlie personality traits are shaped by the local sociocultural context (Fischer, 2017; Gurven et al., 2013).

\section{Limitations \& Future Research}

I used a short self-report measure. This instrument had been used in a number of previous samples, but to date no selfreported personality study has been conducted in a Thai context. The failure to replicate the classic Big Five or FFM structure may be driven by underrepresentation of trait content due to using a short instrument (Fischer \& Fontaine, 2011), semantic shifts during the translation, or the possibility of a different trait structure in this particular culture. A study of Chinese community members (Li et al., 2012) had replicated the five-factor structure, suggesting that the short form of the questionnaire may not be the primary reason. I used a committee translation approach (Hambleton \& Zenisky, 2010) and checked the translation carefully with bilingual researchers and professional translators. Yet, it is not possible to completely rule out alternative interpretations of trait terms in this understudied community. Participants repeatedly commented that the context is important for describing a person in the Thai culture, even though the items themselves are understandable. Potentially, respondents may have used different contexts when answering these items. Administering decontextualized Western-based personality tests in non-Western and traditional communities is challenging (Church et al., 2012). Future research needs to pay more attention to the conceptualization of traits in nonWestern, low-income, and low-education samples (Church et al., 2012; Fischer, 2017; Gurven et al., 2013).

Another problem is the use of negatively phrased items, which often show up as separate factors in both Western and 
non-Western samples (Abubakar \& Fischer, 2012; Church et al., 2012; Gurven et al., 2013). Some of the cross-loadings suggest that item content and valence of the terms may be confounded in this study. Future studies should reconsider the need for positively and negatively phrased items in short instruments (see Hendriks et al., 1999).

One option for future research in field settings is to use recording devices and observations that capture personality relevant behaviors, physiological parameters and natural speech which can then be further analyzed. These unobtrusive measures are independent of self-reports, but can inform us about key behavioral characteristics that signal personality processes and may also be used for more contextualized personality instruments. It might be possible to collect observer ratings (Gurven et al., 2013), although these could be challenged on the basis of observer biases. Spontaneous self-descriptions of participants or solicited reports on their own behavior could be used for lexical analyses and content analysis (Boer \& Fischer, 2012; Boyd \& Pennebaker, 2017; Fischer et al., 2020). In summary, an analysis of a brief personality measure suggested a partially replicable alternative structure. An important frontier for the further development of personality science is to focus on variations in personality structure as captured in self-report measures and examine the origins and functionality of these personality factors in a global perspective.

\section{ACCOUNTS AND ACKNOWLEDGMENTS}

This study was supported by funding from Victoria University of Wellington, New Zealand, and the Marie Curie Cofund Fellowship.

The author has no conflict of interest to declare.

The studies have been conducted following APA ethical standards. Ethical approval was obtained from the School of Psychology Human Ethics Committee under delegated authority of Victoria University of Wellington's Human Ethics Committee.

I would like to thank the editor, Diana Boer, Katja Hanke and Joseph Bulbulia for helpful comments and suggestions on previous drafts of this manuscript. We would also like to thank the local authorities in Phuket and Hatyai, Thailand, for their generous help in facilitating and supporting this study.

\section{REFERENCES}

Abubakar, A., \& Fischer, R. (2012). The Factor Structure of the 12-item General Health Questionnaire in a Literate Kenyan Population: Factor Structure of the GHQ in Kenya. Stress and Health, 28, 248-254. https://doi.org/10.1002/smi.1420

Ashton, M. C., \& Lee, K. (2005). The lexical approach to the study of personality structure: Toward the identification of cross-culturally replicable dimensions of personality variation. Journal of Personality Disorders, 19, 303-308.

https://doi.org/10.1521/pedi.2005.19.3.303
Ashton, M. C., \& Lee, K. (2007). Empirical, Theoretical, and Practical Advantages of the HEXACO Model of Personality Structure. Personality and Social Psychology Review, 11, 150-166. https://doi.org/10.1177/1088868306294907

Ashton, M. C., Lee, K., Perugini, M., Szarota, P., de Vries, R. E., Di Blas, L., Boies, K., \& De Raad, B. (2004). A six-factor structure of personality-descriptive adjectives: Solutions from psycholexical studies in seven languages. Journal of Personality and Social Psychology, 86, 356-366.

https://doi.org/10.1037/0022-3514.86.2.356

Baldasaro, R. E., Shanahan, M. J., \& Bauer, D. J. (2013). Psychometric properties of the mini-IPIP in a large, nationally representative sample of young adults. Journal of Personality Assessment, 95, 74-84.

https://doi.org/10.1080/00223891.2012.700466

Boer, D., \& Fischer, R. (2012). Towards a holistic model of functions of music listening across cultures: A culturally decentred qualitative approach. Psychology of Music, 40, 179-200. https://doi.org/10.1177/0305735610381885

Boyd, R. L., \& Pennebaker, J. W. (2017). Language-based personality: A new approach to personality in a digital world. Current Opinion in Behavioral Sciences, 18, 63-68. https://doi.org/10.1016/j.cobeha.2017.07.017

Cheung, F., Fan, W., \& To, C. (2008). The Chinese Personality Assessment Inventory as a Culturally Relevant Personality Measure in Applied Settings. Social and Personality Psychology Compass, 2, 74-89. https://doi.org/10.1111/j.1751-9004.2007.00045.X

Cheung, F., Leung, K., Zhang, J.-X., Sun, H.-F., Gan, Y.-Q., Song, W.-Z., \& Xie, D. (2001). Indigenous Chinese Personality Constructs: Is the Five-Factor Model Complete? Journal of CrossCultural Psychology, 32, 407-433. https://doi.org/10.1177/0022022101032004003

Cheung, F. M., van de Vijver, F. J. R., \& Leong, F. T. L. (2011). Toward a new approach to the study of personality in culture. American Psychologist, 66, 593-603. https://doi.org/10.1037/a0022389

Church, A. T., Alvarez, J. M., Mai, N. T. Q., French, B. F., Katigbak, M. S., \& Ortiz, F. A. (2011). Are cross-cultural comparisons of personality profiles meaningful? Differential item and facet functioning in the Revised NEO Personality Inventory. Journal of Personality and Social Psychology, 101, 1068-1089. https://doi.org/10.1037/a0025290

Church, A. T., Willmore, S. L., Anderson, A. T., Ochiai, M., Porter, N., Mateo, N. J., Reyes, J. A. S., de Jesús Vargas-Flores, J., Ibáñez-Reyes, J., Alvarez, J. M., Katigbak, M. S., \& Ortiz, F. A. (2012). Cultural differences in implicit theories and self-perceptions of traitedness: Replication and extension with alternative measurement formats and cultural dimensions. Journal of CrossCultural Psychology, 43, 1268-1296.

https://doi.org/10.1177/0022022111428514

Cooper, A. J., Smillie, L. D., \& Corr, P. J. (2010). A confirmatory factor analysis of the Mini-IPIP five-factor model personality scale. Personality and Individual Differences, 48, 688-691. https://doi.org/10.1016/j.paid.2010.01.004

De Raad, B., Barelds, D. P. H., Levert, E., Ostendorf, F., Mlacić, B., Di Blas, L., Hrebícková, M., Szirmák, Z., Szarota, P., Perugini, M., Church, A. T., \& Katigbak, M. S. (2010). Only three factors of personality description are fully replicable across languages: A comparison of 14 trait taxonomies. Journal of Personality and Social Psychology, 98, 160-173. https://doi.org/10.1037/a0017184

De Raad, B., Barelds, D. P. H., Timmerman, M. E., De Roover, K., Mlačić, B., \& Church, A. T. (2014). Towards A Pan-Cultural Personality Structure: Input from 11 Psycholexical Studies. European Journal of Personality, 28, 497-510. https://doi.org/10.1002/per.1953 
Donnellan, M. B., Oswald, F. L., Baird, B. M., \& Lucas, R. E. (2006). The mini-IPIP scales: Tiny-yet-effective measures of the Big Five factors of personality. Psychological Assessment, 18, 192-203. https://doi.org/10.1037/1040-3590.18.2.192

Fischer, R. (2017). Personality, Values, Culture: An Evolutionary Approach. Cambridge University Press. https://doi.org/10.1017/9781316091944

Fischer, R., \& Fontaine, J. R. J. (2011). Methods for investigating structural equivalence. In D. Matsumoto, \& F. Van de Vijver (Eds), Cross-cultural research methods in psychology (pp. 179215). Cambridge University Press.

Fischer, R., \& Karl, J. A. (2019). A Primer to (Cross-Cultural) Multi-Group Invariance Testing Possibilities in R. Frontiers in Psychology, 10. https://doi.org/10.3389/fpsyg.2019.01507

Fischer, R., Karl, J. A., Luczak-Roesch, M., Fetvadjiev, V. H., \& Grener, A. (2020). Tracing Personality Structure in Narratives: A Computational Bottom-Up Approach to Unpack Writers, Characters, and Personality in Historical Context. European Journal of Personality, 34, 917-943. https://doi.org/10.1002/per.2270

Goldberg, L. R. (1990). An alternative "description of personality": The big-five factor structure. Journal of Personality and Social Psychology, 59, 1216-1229. https://doi.org/10.1037//00223514.59.6.1216

Golino, H. F., \& Epskamp, S. (2017). Exploratory graph analysis: A new approach for estimating the number of dimensions in psychological research. PLOS ONE, 12, e0174035. https://doi.org/10.1371/journal.pone.0174035

Golino, H., Shi, D., Christensen, A. P., Garrido, L. E., Nieto, M. D., Sadana, R., Thiyagarajan, J. A., \& Martinez-Molina, A. (2020). Investigating the performance of exploratory graph analysis and traditional techniques to identify the number of latent factors: A simulation and tutorial. Psychological Methods, 25, 292-320. https://doi.org/10.1037/met0000255

Gurven, M. D. (2018). Broadening horizons: Sample diversity and socioecological theory are essential to the future of psychological science. Proceedings of the National Academy of Sciences, 115, 11420-11427. https://doi.org/10.1073/pnas.1720433115

Gurven, M., von Rueden, C., Massenkoff, M., Kaplan, H., \& Lero Vie, M. (2013). How universal is the Big Five? Testing the fivefactor model of personality variation among forager-farmers in the Bolivian Amazon. Journal of Personality and Social Psychology, 104, 354-370. https://doi.org/10.1037/a0030841

Hambleton, R. K., \& Zenisky, A. L. (2010). Translating and Adapting Tests for Cross-Cultural Assessments. In D. Matsumoto \& F. J. R. van de Vijver (Eds.), Cross-Cultural Research Methods in Psychology (pp. 46-70). Cambridge University Press. https://doi.org/10.1017/CBO9780511779381.004

Hendriks, A. A. J., Hofstee, W. K. B., \& De Raad, B. D. (1999).

The Five-Factor Personality Inventory (FFPI). Personality and Individual Differences, 27, 307-325.

https://doi.org/10.1016/S0191-8869(98)00245-1

Hofstede, G. (2001). Culture's Consequences: Comparing Values, Behaviors, Institutions and Organizations Across Nations. SAGE.

Inglehart, R., \& Baker, W. E. (2000). Modernization, cultural change, and the persistence of traditional values. American Sociological Review, 65, 19-51. https://doi.org/10.2307/2657288

Katigbak, M. S., Church, A. T., \& Akamine, T. X. (1996). Crosscultural generalizability of personality dimensions: Relating indigenous and imported dimensions in two cultures. Journal of Personality and Social Psychology, 70, 99-114. https://doi.org/10.1037//0022-3514.70.1.99

Laajaj, R., Macours, K., Pinzon Hernandez, D. A., Arias, O., Gosling, S. D., Potter, J., Rubio-Codina, M., \& Vakis, R. (2019). Challenges to capture the big five personality traits in nonWEIRD populations. Science Advances, 5, eaaw5226. https://doi.org/10.1126/sciadv.aaw5226
Li, Z., Sang, Z., Wang, L., \& Shi, Z. (2012). The Mini-IPIP Scale: Psychometric Features and Relations with PTSD Symptoms of Chinese Earthquake Survivors. Psychological Reports, 111, 641-651. https://doi.org/10.2466/16.12.15.PR0.111.5.641651

Lukaszewski, A. W., Gurven, M., von Rueden, C. R., \& Schmitt, D. P. (2017). What Explains Personality Covariation? A Test of the Socioecological Complexity Hypothesis. Social Psychological and Personality Science, 8, 943-952.

https://doi.org/10.1177/1948550617697175

Marsh, H. W., Hau, K.-T., \& Wen, Z. (2004). In Search of Golden Rules: Comment on Hypothesis-Testing Approaches to Setting Cutoff Values for Fit Indexes and Dangers in Overgeneralizing $\mathrm{Hu}$ and Bentler's (1999) Findings. Structural Equation Modeling: A Multidisciplinary Journal, 11, 320-341. https://doi.org/10.1207/s15328007sem1103_2

McCrae, R. R. (2001). Trait psychology and culture: Exploring intercultural comparisons. Journal of Personality, 69, 819-846. https://doi.org/10.1111/1467-6494.696166

McCrae, R. R., \& John, O. P. (1992). An introduction to the fivefactor model and its applications. Journal of Personality, 60, 175-215. https://doi.org/10.1111/j.1467-6494.1992.tb00970.x

McCrae, R. R., Terracciano, A., \& Personality Profiles of Cultures Project. (2005). Universal features of personality traits from the observer's perspective: Data from 50 cultures. Journal of Personality and Social Psychology, 88, 547-561. https://doi.org/10.1037/0022-3514.88.3.547

McCrae, R. R., Zonderman, A. B., Costa Jr., P. T., Bond, M. H., \& Paunonen, S. V. (1996). Evaluating replicability of factors in the Revised NEO Personality Inventory: Confirmatory factor analysis versus Procrustes rotation. Journal of Personality and Social Psychology, 70, 552-566.

https://doi.org/10.1037/0022-3514.70.3.552

Nel, J. A., Valchev, V. H., Rothmann, S., van de Vijver, F. J. R., Meiring, D., \& de Bruin, G. P. (2012). Exploring the personality structure in the 11 languages of South Africa. Journal of Personality, 80, 915-948.

https://doi.org/10.1111/j.1467-6494.2011.00751.x

Revelle, W. (2021). Psych: Procedures for Psychological, Psychometric, and Personality Research (2.1.9) [Computer software]. https://CRAN.R-project.org/package=psych

Saucier, G., Thalmayer, A. G., Payne, D. L., Carlson, R., Sanogo, L., Ole-Kotikash, L., Church, A. T., Katigbak, M. S., Somer, O., Szarota, P., Szirmák, Z., \& Zhou, X. (2014). A Basic Bivariate Structure of Personality Attributes Evident Across Nine Languages. Journal of Personality, 82, 1-14.

https://doi.org/10.1111/jopy.12028

Schmitt, D. P., Allik, J., McCrae, R. R., \& Benet-Martínez, V. (2007). The Geographic Distribution of Big Five Personality Traits: Patterns and Profiles of Human Self-Description Across 56 Nations. Journal of Cross-Cultural Psychology, 38, 173-212. https://doi.org/10.1177/0022022106297299

Sibley, C. G., Luyten, N., Purnomo, M., Mobberley, A., Wootton, L. W., Hammond, M. D., Sengupta, N., Perry, R., West-Newman, T., Wilson, M. S., McLellan, L., Hoverd, W. J., \& Robertson, A. (2011). The Mini-IPIP6: Validation and extension of a short measure of the Big-Six factors of personality in New Zealand. New Zealand Journal of Psychology, 40, 142-159.

ten Berge, J. M. F. (1986). Some Relationships Between Descriptive Comparisons of Components from Different Studies. Multivariate Behavioral Research, 21, 29-40. https://doi.org/10.1207/s15327906mbr2101_2

Thalmayer, A. G., Job, S., Shino, E. N., Robinson, S. L., \& Saucier,

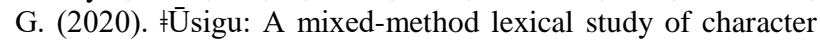
description in Khoekhoegowab. Journal of Personality and Social Psychology. Online publication ahead of print. https://doi.org/10.1037/pspp0000372

Valchev, V. H., Nel, J. A., van de Vijver, F. J. R., Meiring, D., de 
Bruin, G. P., \& Rothmann, S. (2013). Similarities and Differences in Implicit Personality Concepts across Ethnocultural Groups in South Africa. Journal of Cross-Cultural Psychology, 44, 365-388. https://doi.org/10.1177/0022022112443856

Valchev, V. H., van de Vijver, F. J. R., Meiring, D., Nel, J. A., Hill, C., Laher, S., \& Adams, B. G. (2014). Beyond Agreeableness: Social-relational personality concepts from an indigenous and cross-cultural perspective. Journal of Research in Personality, 48, 17-32. https://doi.org/10.1016/j.jrp.2013.10.003

Received October 27, 2021 Accepted November 7, 2021 